\title{
Oxygen consumption and resting energy expenditure during phototherapy in full term and preterm newborn infants
}

\author{
T F Fok, J-S Gu, C N Lim, P C Ng, H L Wong, K W So
}

\begin{abstract}
Objectives-To determine the effect of phototherapy on the oxygen consumption and resting energy expenditure of term and preterm newborn infants.

Methods-A total of 202 infants (gestation 30-42 weeks; body weight $1270-4100 \mathrm{~g}$ ) requiring phototherapy for the treatment of neonatal hyperbilirubinaemia were enrolled in a randomised crossover study. In random sequence, the oxygen consumption and resting energy expenditure were measured twice in each infant by indirect calorimetry, once at the end of six hours of continuous phototherapy and once after a control period of at least six hours without phototherapy. Anterior abdominal wall temperature was servocontrolled at $36.5^{\circ} \mathrm{C}$ throughout the study.

Results-At the end of six hours of continuous phototherapy, oxygen consumption (mean (SD): $6.21(1.35) v 6.26$ (1.51) $\mathrm{ml} / \mathrm{kg}, \mathrm{p}=0.555$ ) and resting energy expenditure $\left(\begin{array}{llll}178.11 & (37.62) & v & 180.37\end{array}\right.$ (43.14) $\mathrm{kJ} / \mathrm{kg} / 24 \mathrm{~h}, \mathrm{p}=0.382$ ) did not differ significantly from those measured after the control period. There were also no significant differences in heart rate, respiratory rate, or rectal temperature. Subgroup analysis of those of gestation $<37$ weeks or $<34$ weeks also showed no effect of phototherapy on either oxygen consumption or resting energy expenditure.
\end{abstract}

Conclusion-Phototherapy has no effect on the metabolic rate of thermally stable term or preterm infants.

(Arch Dis Child Fetal Neonatal Ed 2001;85:F49-F52)

Keywords: phototherapy; oxygen consumption; resting energy expenditure; preterm

Phototherapy may affect the energy metabolism and oxygen consumption of newborn infants by a number of mechanisms. The photo-oxidation of bilirubin in the skin is an oxygen consuming process, and it has been shown that photo-energy accelerates the oxidation of fatty acids. ${ }^{1}$ The metabolic effect of phototherapy, however, appears to be mediated mainly through changes in the infant's thermal environment. Part of the photo-energy, especially that near the infrared range, is converted into heat energy which increases the environmental and skin temperature of the infant. ${ }^{2}{ }^{3}$ Overheating may increase metabolic rate as a result of elevation of the body temperature and increase in insensible water loss. A profound increase in evaporative water loss is seen when sweating is elicited by a rise in body temperature in newborns. ${ }^{4}$ Even without apparent sweating, infants undergoing phototherapy exhibit a significant increase in peripheral blood flow $^{5}$ and transepidermal insensible water loss. A rise in body temperature may also increase respiratory rate and minute ventilation, ${ }^{56}$ leading to increased respiratory water loss. $^{57}$ The increase in evaporative water loss through the skin and respiratory tract consumes a substantial amount of heat energy in the form of latent heat of evaporation, and the increase in muscle activity caused by increased respiratory rate and the discomfort resulting from overheating also increases metabolic rate. ${ }^{8}$ It has been estimated that, in newborns, approximately $2.42 \mathrm{~J}$ of heat is dissipated for each gram of water evaporated. ${ }^{9}{ }^{10}$ The thermal effect on insensible water loss is particularly pronounced in preterm and low birth weight infants ${ }^{591112}$ because of skin factors, including larger surface area in relation to body weight, thinner epidermis, larger water content, and greater permeability.

The thermal effect of phototherapy can be minimised by maintaining a stable environmental temperature using devices such as a plastic blanket or Perspex heat shield. ${ }^{13-16}$ Kjartansson et al reported that, in both full term and preterm infants whose skin temperature was maintained at a constant level by servocontrol, phototherapy was not associated with any significant change in oxygen consumption or water loss through the skin ${ }^{17}$ or the respiratory tract. ${ }^{18}$ This study, however, included only a relatively small number of infants who had received phototherapy for a short time (one hour) before measurement. To evaluate the effect of phototherapy on the energy metabolism of newborns, the present study was carried out to study the oxygen consumption and resting energy expenditure of a group of full term and preterm infants after prolonged phototherapy.

\section{Subjects and method}

The study was approved by the clinical research ethics committee of the Chinese University of Hong Kong. Stable full term or preterm infants admitted consecutively to the neonatal unit for treatment of hyperbilirubinaemia with phototherapy were enrolled if the following criteria were satisfied: absence of haemolysis or coexisting illness; being fed exclusively on formula milk; parental consent. Infants with the following conditions were excluded: abnormal rectal temperature 
$\left(>37.5^{\circ} \mathrm{C}\right.$ or $\left.<36.5^{\circ} \mathrm{C}\right)$; major congenital anomalies; perinatal asphyxia (Apgar score $<7$ at one or five minutes after birth); confirmed or suspected sepsis, or presence of risk factors for infection including prolonged rupture of amniotic membrane for $\geqslant 18$ hours, and maternal infection or fever; maternal metabolic diseases including diabetes mellitus and hyperthyroidism or hypothyroidism; requiring assisted ventilation, supplemental oxygen, intravenous fluid, or any medication. In random sequence determined by the computer, oxygen consumption and energy expenditure of each infant was measured twice consecutively. One measurement was taken during phototherapy after the infant had received the treatment continuously for six hours. The other measurement was obtained after a control period of at least six hours. The latter measurement was performed either before the start of phototherapy or after the phototherapy light had been turned off for at least six hours. Randomisation was carried out using the sealed envelope method. Throughout the study, the infant was nursed naked inside a double walled infant incubator and monitored electronically for heart rate, respiratory rate, and rectal temperature. The values of these variables were recorded immediately before each calorimetry measurement. Each infant was given the same amount of formula feed at three hour intervals. A thermistor was attached to the anterior abdominal wall to maintain the skin temperature at $36.5^{\circ} \mathrm{C}$ using the servocontrol device of the incubator. The thermistor was protected from the phototherapy light with a heat reflecting adhesive patch. The relative humidity and temperature of the environment were maintained at $60 \%$ and $26^{\circ} \mathrm{C}$ respectively, with no extra humidification being added to the inside of the incubator. The radiant energy emitted from the phototherapy units was $8.1-14.5 \mu \mathrm{W} / \mathrm{cm}^{2} / \mathrm{nm}$ at the level of the infant, as measured with a phototherapy radiometer (Fluoro-lite Metre; Airshield-Minolta, Hatboro, Pennsylvania, USA).

Table $1 \mathrm{VO}_{2}, \mathrm{VCO}_{2}$, and resting energy expenditure of the study infants after six hours of phototherapy or after at least six hours of control period

\begin{tabular}{|c|c|c|c|}
\hline & $\begin{array}{l}\text { At the end of } 6 \text { h of } \\
\text { phototherapy }\end{array}$ & $\begin{array}{l}\text { After }>6 h \text { of } \\
\text { control period }\end{array}$ & $p$ Value \\
\hline \multicolumn{4}{|l|}{ All infants $(n=202)$} \\
\hline Heart rate (beats/min) & $136.0 \quad(16.8)$ & $135.3(12.8)$ & 0.572 \\
\hline Respiratory rate (breaths/min) & $42.7 \quad(5.83)$ & $42.3(6.08)$ & 0.233 \\
\hline Rectal temperature $\left({ }^{\circ} \mathrm{C}\right)$ & $37.0 \quad(0.27)$ & $37.1(0.34)$ & 0.122 \\
\hline $\mathrm{VCO}_{2}(\mathrm{ml} / \mathrm{kg} / \mathrm{min})$ & $5.38(1.21)$ & $5.48(1.29)$ & 0.223 \\
\hline $\mathrm{VO}_{2}(\mathrm{ml} / \mathrm{kg} / \mathrm{min})$ & $6.21(1.35)$ & $6.26(1.51)$ & 0.554 \\
\hline Energy expenditure $(\mathrm{kJ} / \mathrm{kg} / 24 \mathrm{~h})$ & $178.11(37.62)$ & $180.37(43.14)$ & 0.382 \\
\hline \multicolumn{4}{|l|}{ Infants of gestation $\geqslant 37$ weeks $(n=118)$} \\
\hline $\mathrm{VCO}_{2}(\mathrm{ml} / \mathrm{kg} / \mathrm{min})$ & $5.67(1.11)$ & $5.85(1.15)$ & 0.095 \\
\hline $\mathrm{VO}_{2}(\mathrm{ml} / \mathrm{kg} / \mathrm{min})$ & $6.78(1.05)$ & $6.90(1.30)$ & 0.355 \\
\hline Energy expenditure $(\mathrm{kJ} / \mathrm{kg} / 24 \mathrm{~h})$ & $192.24(30.14)$ & $196.96(37.91)$ & 0.194 \\
\hline \multicolumn{4}{|l|}{ Infants of gestation $<37$ weeks $(n=84)$} \\
\hline $\mathrm{VCO}_{2}(\mathrm{ml} / \mathrm{kg} / \mathrm{min})$ & $4.97(1.24)$ & $4.95(1.29)$ & 0.801 \\
\hline $\mathrm{Vo}_{2}(\mathrm{ml} / \mathrm{kg} / \mathrm{min})$ & $5.41(1.32)$ & $5.37(1.32)$ & 0.771 \\
\hline Energy expenditure $(\mathrm{kJ} / \mathrm{kg} / 24 \mathrm{~h})$ & $158.21(38.29)$ & $157.08(39.25)$ & 0.748 \\
\hline \multicolumn{4}{|l|}{ Infants of gestation $<34$ weeks $(n=20)$} \\
\hline $\mathrm{VCO}_{2}(\mathrm{ml} / \mathrm{kg} / \mathrm{min})$ & $5.52(1.46)$ & $5.41(1.20)$ & 0.533 \\
\hline $\mathrm{Vo}_{2}(\mathrm{ml} / \mathrm{kg} / \mathrm{min})$ & $5.71(1.47)$ & $5.67(1.24)$ & 0.844 \\
\hline Energy expenditure $(\mathrm{kJ} / \mathrm{kg} / 24 \mathrm{~h})$ & $169.08(46.44)$ & $166.82(36.87)$ & 0.724 \\
\hline
\end{tabular}

Oxygen consumption $\left(\mathrm{VO}_{2}\right)$ and carbon dioxide production $\left(\mathrm{VCO}_{2}\right)$ were measured by indirect calorimetry using a Deltatrac metabolic monitor (Deltatrac II MBM-200; Instrumentarium Corp, Helsinki, Finland). During measurements, the infant was covered with an airtight transparent plastic canopy. The metabolic monitor generated a constant airflow of 3 litres/min through the canopy and back to the monitor. All the exhaled gas was collected into this constant flow. $\mathrm{VO}_{2}$ and $\mathrm{VCO}_{2}$ were calculated every minute from the difference in the oxygen and carbon dioxide concentration of the inhaled and exhaled gas respectively, after adjustment to standard temperature $\left(0^{\circ} \mathrm{C}\right)$ and pressure $(760 \mathrm{~mm} \mathrm{Hg}$ or $101.3 \mathrm{kPa})$ conditions. The calculation of resting energy expenditure (REE) was based on the Weir formula ${ }^{19}$ with modification by the manufacturer:

$\mathrm{REE}=5.50 \mathrm{VO}_{2}+1.76 \mathrm{VCO}_{2}-1.99 \mathrm{U}_{\mathrm{N}}$

where $U_{N}$ is the urinary nitrogen excretion in $\mathrm{g} / 24 \mathrm{~h}$. Urinary nitrogen excretion was considered to be negligible in the calculation because the amount is small in the first few days of life and the measurement error resulting from its omission is less than $1 \%{ }^{20}$ Each measurement was continued for 15 minutes, and the mean value of each variable obtained. All the measurements were carried out about two hours after a feed when the infant was asleep or in a quiet non-agitated state. None of the infants was given any sedation.

The measurements obtained on the two occasions were compared by paired $t$ test. All values are expressed as mean (SD). Differences were considered to be statistically significant if the $\alpha$ error was $5 \%$ or less.

\section{Results}

The study infants had a gestational age of 37.2 (2.8) weeks (range 30.1-42.1) and birth weight of 2780 (676) g (range 1400-4100). Postnatal age and body weight at the time of the study were 4.8 (2.1) days (range 1-11) and 2740 (701) g (range 1270-4052) respectively. The birth weights of all the infants were appropriate for gestation, as determined from the local gestation specific birth weight chart. ${ }^{21}$ Table 1 gives the variables measured at the end of either six hours of continuous phototherapy or the control period. Thermal stability was maintained by servocontrol throughout the experiment, and rectal temperatures were similar on the two occasions $(p=0.122)$. There were no differences in heart rate $(\mathrm{p}=0.572)$, respiratory rate $(\mathrm{p}=0.233), \mathrm{Vo}_{2}$ $(\mathrm{p}=0.554), \mathrm{VCO}_{2}(\mathrm{p}=0.223)$, or the calculated resting energy expenditure $(p=0.382)$. Subgroup analysis of $\mathrm{VO}_{2}, \mathrm{VCO}_{2}$, and energy expenditure was carried out separately on the term and preterm infants. After the two study periods, there were no significant differences in any of these variables in infants of gestation $\geqslant 37$ weeks $\left(\mathrm{VO}_{2}: \mathrm{p}=0.355 ; \mathrm{VCO}_{2}: \mathrm{p}=0.095\right.$; energy expenditure: $\mathrm{p}=0.194$ ) or those of gestation < 37 weeks $\left(\mathrm{VO}_{2}: \mathrm{p}=0.771 ; \mathrm{VCO}_{2}\right.$ : $\mathrm{p}=0.801$; energy expenditure: $\mathrm{p}=0.748$ ) 
Further analysis of the preterm infants also showed no significant differences in $\mathrm{VO}_{2}, \mathrm{VCO}_{2}$, or energy expenditure after the two study periods among the infants of gestation $<34$ weeks $\left(\mathrm{Vo}_{2}: \mathrm{p}=0.844 ; \mathrm{VCO}_{2}: \mathrm{p}=0.533\right.$; energy expenditure: $\mathrm{p}=0.724$ ).

\section{Discussion}

The metabolic effects of phototherapy on newborn infants have always been a concern of paediatricians. Previous workers have shown impaired growth in infants during phototherapy. ${ }^{22}$ Variation in $\mathrm{VO}_{2}$ has been shown in moderately low birth weight infants receiving phototherapy in a cot or inside an incubator. ${ }^{3}$ These metabolic effects have been attributed to an increase in insensible water loss ${ }^{1123}$ or elevation of the environmental temperature during phototherapy. ${ }^{3}$ In both full term and preterm infants, earlier studies have shown a significant increase in insensible water loss during phototherapy. ${ }^{511} 23$ However, in these early studies, the measurement of insensible water loss was based on insensible weight loss estimated by intermittent or continuous weighing of the infants, with allowance made for water intake in food and water of oxidation, plus water lost in urine and stool. It has been pointed out by Doyle and Sinclair ${ }^{24}$ that the measurements made in these studies were subjected to systematic errors because the accuracy of the estimate of insensible water loss depended on the estimates of water intake and water lost in urine and stool and the validity of the assumptions about water of oxidation. Other sources of error included absorption of water on to the weighing apparatus, and the potential hygroscopic properties of materials used for clothing or bedding. It has also been shown that the weight reading of the Potter baby scale used in some of these studies ${ }^{11}$ is affected by temperature change. ${ }^{25}{ }^{26}$ More precise estimation of the transepidermal and respiratory insensible water loss of newborns during phototherapy has been made by Kjartansson $e$ e $^{17}{ }^{18}$ using an evaporimeter and a mass spectrometer respectively. In 11 full term and eight preterm infants whose skin temperature was maintained at a constant level by servocontrol during phototherapy, this group of workers did not observe any significant change in $\mathrm{Vo}_{2}$ or water loss through the skin or the respiratory tract. This study was, however, limited by the small number of infants, and the fact that the infants had received phototherapy for only one hour before measurement. In the present study, the infants did not show any increase in $\mathrm{VO}_{2}$ or resting energy expenditure after prolonged phototherapy for six hours. Our sample size of 222 has a power of $80 \%$ in detecting an increase of $2 \%$ in $\mathrm{Vo}_{2}$ and resting energy expenditure. The Deltatrac metabolic monitor used in our study uses a paramagnetic analyser for oxygen detection, which is based on differential pressure detection of inspiratory and mixed expiratory oxygen partial pressure. This enables direct measurement of the inspiratory minus expiratory oxygen fraction. The carbon dioxide fraction is detected by infrared absorption. The neonatal mode of the monitor allows measurement of small volume $\mathrm{Vo}_{2}$. Its sensitivity and reproducibility has been validated, and the error of measurement has been estimated to be $1.9-4 \% .^{27-29}$ The method allows fast and reproducible measurements without causing disturbance to the infants, which may affect metabolic rate. ${ }^{29}$ Our findings thus confirmed that the radiant energy from the phototherapy light does not significantly change the metabolic rate of thermally stable full term and preterm newborns. We did not measure skin or respiratory insensible water loss. Theoretically, because approximately $2.42 \mathrm{~J}$ is dissipated for every gram of water evaporated, our findings would imply that insensible water loss is not substantially increased by phototherapy. This would be consistent with the observations made by Kjartansson et $a l^{17}{ }^{18}$ in heat balanced infants. In full term infants ${ }^{30}$ and newborn lambs, ${ }^{31}$ Riesenfeld et al have shown that a high environmental temperature results in a significant increase in insensible water loss without any appreciable change in oxygen consumption. It thus appears that an increase in insensible water loss is caused principally by heat stress and not by photo-energy per se. One possible explanation for the lack of measurable increase in $\mathrm{VO}_{2}$ in the subjects in the study of Riesenfeld et al is that during heat stress, transepidermal and respiratory insensible water loss is increased as a mechanism to dissipate heat to maintain a normal body temperature: when an equilibrium state is reached, heat gain from an external source and evaporative heat loss are balanced out, resulting in a measurable increase in insensible water loss but little change in metabolic rate. Infants receiving phototherapy with their skin temperature under servocontrol are not exposed to heat stress, and therefore there is little change in either $\mathrm{VO}_{2}$ or insensible water loss. It has long been the practice for paediatricians to provide infants with extra fluid to compensate for increased insensible water loss during phototherapy. Although our study did not provide any direct information on the effect of phototherapy on insensible water loss, our findings, plus those of previous workers, ${ }^{17} 183031$ do suggest that there may be a need to use different strategies for rehydrating infants receiving phototherapy with and without servocontrol of their body temperature. Further studies are required to clarify this important clinical problem.

We thank Mr Eric Wong, Statistician, Centre of Clinical Trials and Epidemiology Research, The Chinese University of Hong Kong for statistical assistance.

1 Ostrea EM Jr, Fleury CA, Balun JE, et al. Accelerated degradation of essential fatty acids as a complication of phototherapy. F Pediatr 1983;102:617-19

$2 \mathrm{Wu}$ PY, Berdahl M. Irradiance in incubators under phototherapy lamps. F Pediatr 1974;84:754-55.

3 Smales ORC. Effect of phototherapy on thermal environment of the newborn. Arch Dis Child 1978;53:172-4.

4 Hammarlund K, Nilsson GE, Oberg PA, et al. Transepidermal water loss in newborn infants. II. Relation to activity and body temperature. Acta Paediatr Scand 1979;68:371-

5 Oh W, Yao AC, Hanson JS, et al. Peripheral circulatory response to phototherapy in newborn infants. Acta Paediatr Scand 1973;62:49-54.

$6 \mathrm{Oh} \mathrm{W}$, Karecki H. Phototherapy and insensible water loss in the newborn infant. Am $\mathcal{F}$ Dis Child 1972;124:230-2.

7 Bell EF, Neidich GA, Cashore WJ, et al. Combined effect of radiant warmer and phototherapy on insensible water loss in low birth weight infants. F Pediatr 1979;94:810-13. 
8 Riesenfeld T, Hammarlund K, Sedin G. Respiratory water loss in relation to activity in fullterm infants on their first

9 Hey EN, Katz G. Evaporative water loss in the new-born baby. F Physiol (Lond) 1969;200:589-603.

10 Swenson O, Egan TJ. Measurement of postoperative water requirements in infants. F Pediatr Surg 1969;4:133-41.

$11 \mathrm{Wu}$ PY, Hodgman JE. Insensible water loss in preterm infants: changes with postnatal development and nonionizing radiant energy. Pediatrics 1974;54:704-12.

12 Wu PY, Moosa A. Effect of phototherapy on nitrogen and electrolyte levels and water balance in jaundiced preterm infants. Pediatrics 1978;61:193-8.

13 Hey EN, Mount LE. Heat losses from babies in incubators. Arch Dis Child 1967:42:75-84.

14 Bell EF, Weinstein MR, Oh W. Heat balance in premature infants: comparative effects of convectively heated incubator and radiant warmer, with and without plastic heat tor and radiant warmer, with

15 Baumgart S, Engle WD, Fox WW, et al. Effect of heat shielding on convective and evaporative heat losses and on
radiant heat transfer to the premature infant. 7 Pediatr radiant heat transf

16 Marks KH, Friedman Z, Maisels MJ. A simple device for reducing insensible water loss in low-birth-weight infants. Pediatrics 1977;60:223-6.

17 Kjartansson S, Hammarlund K, Sedin G. Insensible wate loss from the skin during phototherapy in term and preterm infants. Acta Paediatr 1992;81:764-8.

18 Kjartansson S, Hammarlund K, Riesenfeld T, et al. Respiratory water loss and oxygen consumption in newborn infants during phototherapy. Acta Paediatr 1992;81:76973.

19 Weir JB de V. New methods for calculating metabolic rate with special reference to protein metabolism. F Physiol (Lond) 1949;109:1-9.
20 Thureen PJ, Phillips RE, DeMarie MP, et al. Technical and methodologic considerations for performance of indirect calorimetry in ventilated and nonventilated preterm infants. Crit Care Med 1997;25:171-80.

21 Fok TF, Lam TK, Lee N, et al. A prospective study on the intrauterine growth of Hong Kong Chinese. Biol Neonate 1987;51:312-23.

22 Wu PY, Lim RC, Hodgman JE, et al. Effect of phototherapy in preterm infants on growth in the neonatal period. $f$ Pediatr 1974;85:563-6.

23 Wu PYK, Hodgman JE. Changes in insensible water loss in infants with and without phototherapy. Clin Res 1972;20:284.

24 Doyle LW, Sinclair JC. Insensible water loss in newborn infants. Clin Perinatol 1982;9:453-81.

25 Darnall RA Jr. Insensible weight loss measurements in newborn infants: possible overestimation with the Potter baby scale. F Pediatr 1981;99:794-7.

26 Doyle LW, Sinclair JC. Temperature changes and the Potter baby scale [letter]. F Pediatr 1982;100:1006.

27 Takala J, Keinanen O, Vaisanen P, et al. Measurement of gas exchange in intensive care: laboratory and clinical
validation of a new device. Crit Care Med 1989;17:1041-7.

28 Ronco JJ, Phang PT. Validation of an indirect calorimeter to measure oxygen consumption in critically ill patients. $\mathcal{F}$ Crit Care 1991;6:36-41.

29 Weyland W, Weyland A, Fritz U, et al. A new paediatric metabolic monitor. Intensive Care Med 1994;20:51-7.

30 Riesenfeld T, Hammarlund K, Sedin G. The effect of a warm environment on respiratory water loss in fullterm newborn infants on their first day after birth. Acta Paediatr Scand 1990;79:893-8.

31 Riesenfeld T, Hammarlund K, Jonzon A, et al. Influence of radiant heat stress on respiratory water loss in new-born lambs. Biol Neonate 1988;53:290-4. 